\title{
Soil mercury spatial variations in the fault zone and corresponding influence factors
}

\author{
Xiaolong Sun ${ }^{1, *}$, Xueyun $\mathrm{Si}^{2}$, Yang Xiang ${ }^{3}$, and Dongying Liu ${ }^{1}$ \\ ${ }^{1}$ Key Laboratory of Crustal Dynamics, Institute of Crustal Dynamics, China Earthquake Administration, Beijing, China \\ ${ }^{2}$ Earthquake Administration of Ningxia Hui Autonomous Region, Yinchuan, China \\ ${ }^{3}$ Earthquake Agency of Xinjiang Uygur Autonomous Region, Urumqi, China
}

\section{Article history: \\ Received 23 March 2016 \\ Revised 23 September 2016 \\ Accepted 29 September 2016 \\ Keywords: \\ Fault zone, Soil mercury gas, Concentrations, Influence factor \\ Citation:}

Sun, X., X. Si, Y. Xiang, and D. Liu, 2017: Soil mercury spatial variations in the fault zone and corresponding influence factors. Terr. Atmos. Ocean. Sci., 28, 283-294, doi: 10.3319/TAO.2016.09.29.02

\begin{abstract}
Field measurements were performed using a LUMEX RA-915+ mercury vapour analyser to determine the gaseous mercury $(\mathrm{Hg})$ concentrations in the soils of the North China plain, Loess Plateau, Changping District, Haiyuan fault zone, and north Beiluntai (BLT) fault at the edge of south Tianshan. The factors affecting the soil gas $\mathrm{Hg}$ concentration, such as the sampler type, test hole depth, soil characteristics, fault characteristics, and the mechanisms of their influence are discussed in terms of a gas diffusion equation. The results show that (1) the soil gas $\mathrm{Hg}$ concentration is affected mainly by the time lapse between the hole drilling and measurement, test hole depth and sampler shape; (2) the measured soil gas $\mathrm{Hg}$ concentration agrees well with the gas diffusion equation analytical solution, and the curve shape is closely related to the degree of $\mathrm{Hg}$ enrichment in the soil and the soil density; and (3) the soil gas concentration in the fracture zone is largely affected by the rock type, tectonics, the fault slip rate, the degree of fault locking, the development degree of fractures between the hanging wall and footwall, and the degree of fracture locking because these factors can alter the $\mathrm{Hg}$ upward transport channels and degree of surface enrichment. The effects of these factors on the diffusion coefficient in shallow soil layers are insignificant. The diffusion coefficient $D$ depends on the particle size, density and porosity of the soil materials.
\end{abstract}

\section{INTRODUCTION}

Mercury $(\mathrm{Hg})$ can be emitted into the atmosphere via several natural processes, including geological activity (in particular, volcanic, and geothermal emissions). It can also be easily enriched in faults due to its unique physical and chemical properties, and it can migrate from deep layers up to the surface along a fault or rock fracture due to the presence of a fluid carrier or a pressure gradient (Jin et al. 1989; Zhang et al. 2014). Mercury is widely used in earthquake monitoring and prediction and active fault detection in China (Tang et al. 2004; Liu 2006). For example, anomalous mercury contents in wells or springs have been linked to earthquakes (Zhang et al. 2005), and gaseous mercury concentrations in soils have been used to detect buried active faults (Wang et al. 1991, 2006; Li et al. 2013). Because mercury is an effective tool for tracing deep fluid activity

\footnotetext{
* Corresponding author

E-mail:xlsun04@163.com
}

(Stoffers et al. 1999), it plays an important role in revealing the relation between fluid activity in fault zones and the mechanisms by which strong earthquakes occur.

The size and dynamics of the gas mercury pool in soil might play an important role in atmospheric $\mathrm{Hg}$ fluxes (Johnson and Lindberg 1995; Zhang and Lindberg 1999; Sigler and Lee 2006; Moore et al. 2011). Many soil processes might influence the conversion of $\mathrm{Hg}$ (II) into gaseous elemental mercury (GEM), which can be released into the atmosphere (Zhang and Lindberg 1999). Soil gas mercury concentrations might change much more slowly and be affected by more environmental parameters than the total gaseous mercury (TGM) flux in soils (Moore and Castro 2012). For example, the soil temperature, redox potential, moisture content, and organic matter content significantly affect the TGM concentration in forest soils. Studies have shown that higher soil temperatures can increase atmospheric TGM fluxes (Gustin et al. 1997; Choi and Holsen 
2009; Lin et al. 2010) and lead to higher TGM concentrations in background soils (Sigler and Lee 2006). The soil redox potential might affect soil TGM concentrations by changing the availability of electrons for oxidation-reduction reactions involving $\mathrm{Hg}(\mathrm{II})$ and GEM (Schuster 1991; Zhang and Lindberg 1999; Obrist et al. 2009). Furthermore, an increase in the soil moisture content often leads to a decrease in the soil redox potential, which can promote $\mathrm{Hg}$ (II) reduction to GEM (Zárate-Valdez et al. 2006). Soil organic matter (SOM) has been shown to provide $\mathrm{Hg}$ (II) binding sites (Meili 1991; Skyllberg et al. 2006). If the $\mathrm{Hg}$ (II) bound to SOM is reduced to GEM, an increase in the $\mathrm{Hg}$ (II) content might result in an increase in the soil TGM concentration (Gu et al. 2011).

In this study, a portable mercury vapour analyser (model RA-915+) was used to measure soil gas Hg concentrations in the field. The sampling method, sampling depth and characteristics of the surface soil layer effects on the gaseous $\mathrm{Hg}$ concentration are discussed in terms of a gas diffusion model. The Hg concentration soil gas spatial distribution across and along a fault is analysed.

\section{SAMPLING AND METHODS}

The mercury concentrations in different soils were measured using a LUMEX RA-915+ analyser (from University of British Columbia, CERM3). It uses a Zeeman process (Zeeman atomic absorption spectrometry with high frequency modulation of light polarization) to eliminate interference with the measurements (Špirić and Mashyanov 2000). The RA-915+ Zeeman mercury spectrometer is suitable for the direct determination (without a pre-concentration step in the absorption trap) of mercury concentrations in various samples, such as air, water, soil, food, coal, and oil (Sholupov et al. 2004; Cordy et al. 2011).

Figure 1 illustrates the set-up for measuring soil gas $\mathrm{Hg}$ concentrations. Drilling steel is used first to drill a $30 \mathrm{~mm}$ diameter hole in the soil with a depth of $80 \mathrm{~cm}$ to take soil samples. A pyramidal gas sampler is immediately inserted into the hole after removing the drill bit. Before each measurement, a certain amount of gas is fed into and then expelled out of the sampler to remove any foreign gas from the sampler and the rubber tube between the sampler and detector. The RA-915+ mercury vapour meter displays an instantaneous gaseous $\mathrm{Hg}$ concentration every second and generates an average concentration, i.e., the recorded gaseous $\mathrm{Hg}$ concentration, every ten seconds.

An air extraction pump inside the instrument first extracts gas from the test hole and feeds it into the sampler. The gaseous $\mathrm{Hg}$ concentration is then measured by the instrument. Gases in the surrounding soils continuously diffuse through the soil pores towards the test hole, supplying gas to the test hole. The diffusion rate is closely related to the soil porosity. The gas diffusion process through the sur- rounding soils towards the test hole is similar to diffusion through fluids, which can be mathematically described as diffusion equation (Aral and Liao 1996):

$\frac{\partial C}{\partial t}=D\left(\frac{\partial^{2} C}{\partial x^{2}}+\frac{\partial^{2} C}{\partial y^{2}}+\frac{\partial^{2} C}{\partial z^{2}}\right)$

where $C$ is the gaseous $\mathrm{Hg}$ concentration; $D$ is the diffusion coefficient; $t$ is time; and $x, y$, and $z$ represent the spatial coordinate position. Assuming that the soils near the test hole are isotropic, Eq. (1) can be simplified in spherical coordinates to Eq. (2) with the following boundary conditions:

$\left.\begin{array}{l}\frac{\partial C}{\partial t}=\frac{D}{R^{2}} \cdot \frac{\partial}{\partial R}\left(R^{2} \frac{\partial C}{\partial R}\right) \\ \left.C(R, t)\right|_{t=0}=0 \\ \left.C(R, t)\right|_{R=\infty}=0 \\ \left.C(R, t)\right|_{R=0}<\infty \\ \int_{0}^{\infty} C \cdot n \cdot 4 \pi R^{2} d R=m\end{array}\right\}$

where $R$ is the distance to the spherical centre, $n$ is the porosity, and $m$ is the gaseous $\mathrm{Hg}$ content per unit soil volume. The analytical solution can be obtained by solving Eq. (2) using the Boltzman transform (Chen and Li 1996):

$C(R, t)=\frac{m}{8 n(\pi D t)^{\frac{3}{2}}} e^{-\frac{R^{2}}{4 D t}}$

Equation (3) gives the concentration at an arbitrary spatial point $R$ if the corresponding time $t$ is given in onedimensional space. The dimensions of $C, R, D, \mathrm{~m} / \mathrm{n}$, and $t$ are $\left[\mathrm{M} / \mathrm{L}^{3}\right],[\mathrm{L}],\left[\mathrm{L}^{2} / \mathrm{T}\right],[\mathrm{M}]$, and $[\mathrm{T}]$ in this equation, respectively. Equation (3) shows that the concentration at point $R$ is affected mainly by the gaseous $\mathrm{Hg}$ content $m / n$ of the soil and the diffusion coefficient $D$. As shown in

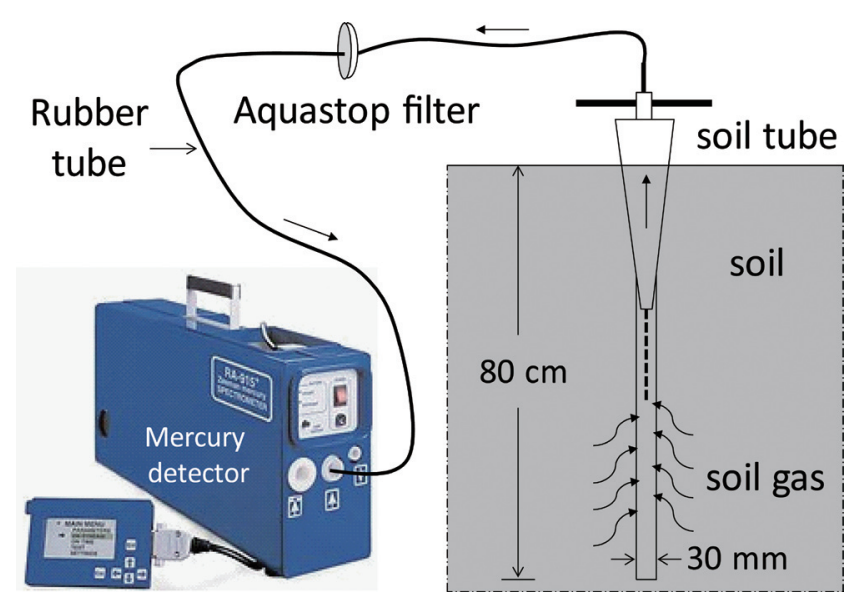

Fig. 1. Soil gas mercury measurement. (Color online only) 
Fig. 2, the $m / n$ value significantly impacts the maximum value of the concentration curve (Fig. 2a), and the diffusion coefficient mainly affects the shape of the concentration curve (Fig. 2b), i.e., the rates at which the concentration increases and decreases.

\section{RESULTS AND DISCUSSION}

Using the previously described sampling method, soil gas $\mathrm{Hg}$ concentrations were measured in different areas of China to determine the influence factors, such as the sampler type, test hole depth, soil characteristics, fracture zone characteristics, and tectonism, for soil gas $\mathrm{Hg}$ concentration in the field.

\subsection{Test Hole Depth and Sampler Type Effects}

The sampler type and test hole depth effects on the measured soil gas $\mathrm{Hg}$ concentrations in the Changping District of Beijing, China were studied. The soils in this area are mainly quaternary, with the sampling sites located mostly in idle farmlands. Although crops were not being farmed at these sites during the research period, the soil porosity and components in the shallow layers (approximately $30 \mathrm{~cm}$ ) might have been affected by human activities, such as fertilization and irrigation and by crop root systems. These factors, however, should not alter the sampler type and test hole depth effects on the soil gas $\mathrm{Hg}$ concentration. Figure 3 shows the soil gas $\mathrm{Hg}$ concentrations measured in different test holes using different samplers. The open circles represent the measured concentrations and the solid lines represent the fitted curve obtained using Eq. (3).

As shown in Fig. 3, a pyramidal sampler was used for some of the soil gas $\mathrm{Hg}$ concentration measurements. The Y50N and Y80N curves represent soil gas $\mathrm{Hg}$ concentrations measured in new test holes at depths of 50 and $80 \mathrm{~cm}$, respectively. The measured gaseous $\mathrm{Hg}$ concentrations and the parameters $m / n$ and $D$ of the fitted curve are higher for the deeper test hole than for the shallower test hole. As $\mathrm{Hg}$ gas in the deep earth is enriched and released out continuously, the gas closer to the surface escapes into the atmosphere easier. A deeper sampling hole is closer to the $\mathrm{Hg}$ source area. Higher $\mathrm{Hg}$ concentrations were therefore detected in the deeper sampling hole.

As shown in Fig. 3, a columnar sampler was used to measure the soil gas $\mathrm{Hg}$ concentrations for the S50N and S80O curves. Specifically, the S50N curve shows the soil gas $\mathrm{Hg}$ concentrations measured in a new test hole with a depth of $50 \mathrm{~cm}$ (the measurements were performed immediately after drilling the hole with a drilling steel), and the S80O curve shows the soil gas $\mathrm{Hg}$ concentrations measured in an old test hole with a depth of $80 \mathrm{~cm}$. The gaseous $\mathrm{Hg}$ concentrations measured in the new test hole are slightly higher than those measured in the old test hole (after drilling the hole the gaseous $\mathrm{Hg}$ concentration was measured twice, once immediately after drilling and once 30 minutes later. The recorded gaseous $\mathrm{Hg}$ concentration in the old test hole is from the second measurement). Although the new test hole is shallower than the old test hole, the $m / n$ value for the old test hole is smaller because the initially enriched gaseous $\mathrm{Hg}$ in the test hole and from the surrounding soils was mostly extracted during the first measurement, whereas during the second measurement, the detected gas was mostly supplied by gas diffusion from more distant areas to the test hole, resulting in a lower measured value. The soil gas $\mathrm{Hg}$ concentration measured in the old test hole during the second measurement is apparently lower than that measured during the first measurement, but the diffusion coefficient $D$ remained constant.

The curves in Fig. 3 indicate that the sampler shape also significantly affects the measured soil gas $\mathrm{Hg}$ concentration. Generally speaking, the values measured using the pyramidal sampler are clearly higher than those measured using the columnar sampler. From a new $50 \mathrm{~cm}$ test hole (at the same sampling site using the same instrument and method with the same measurement duration), the concentration measured
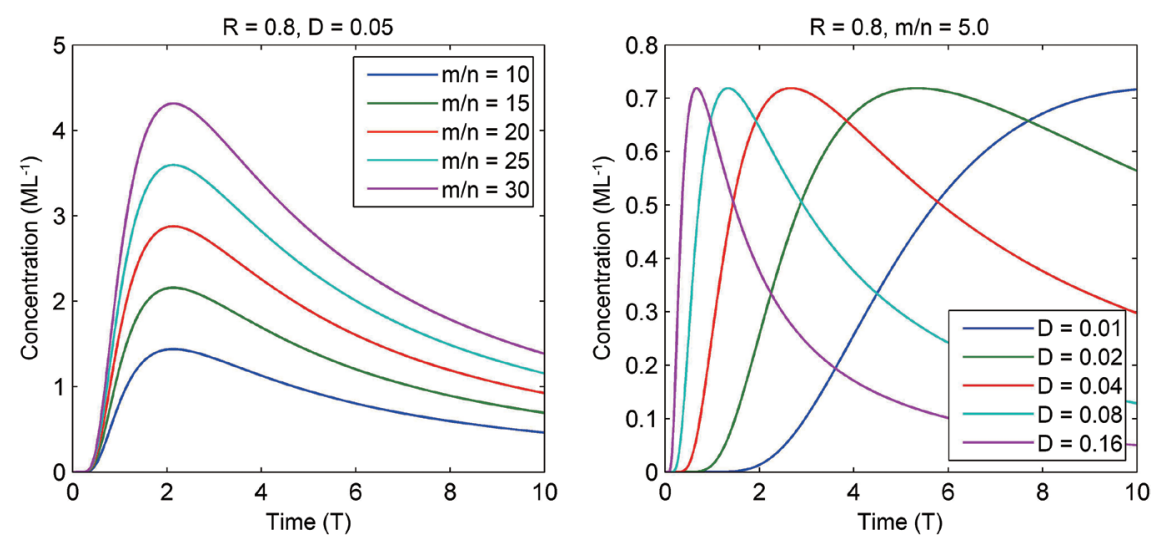

Fig. 2. Degree of enrichment $m / n$ and diffusion coefficient $D$ effects on the concentration. (Color online only) 

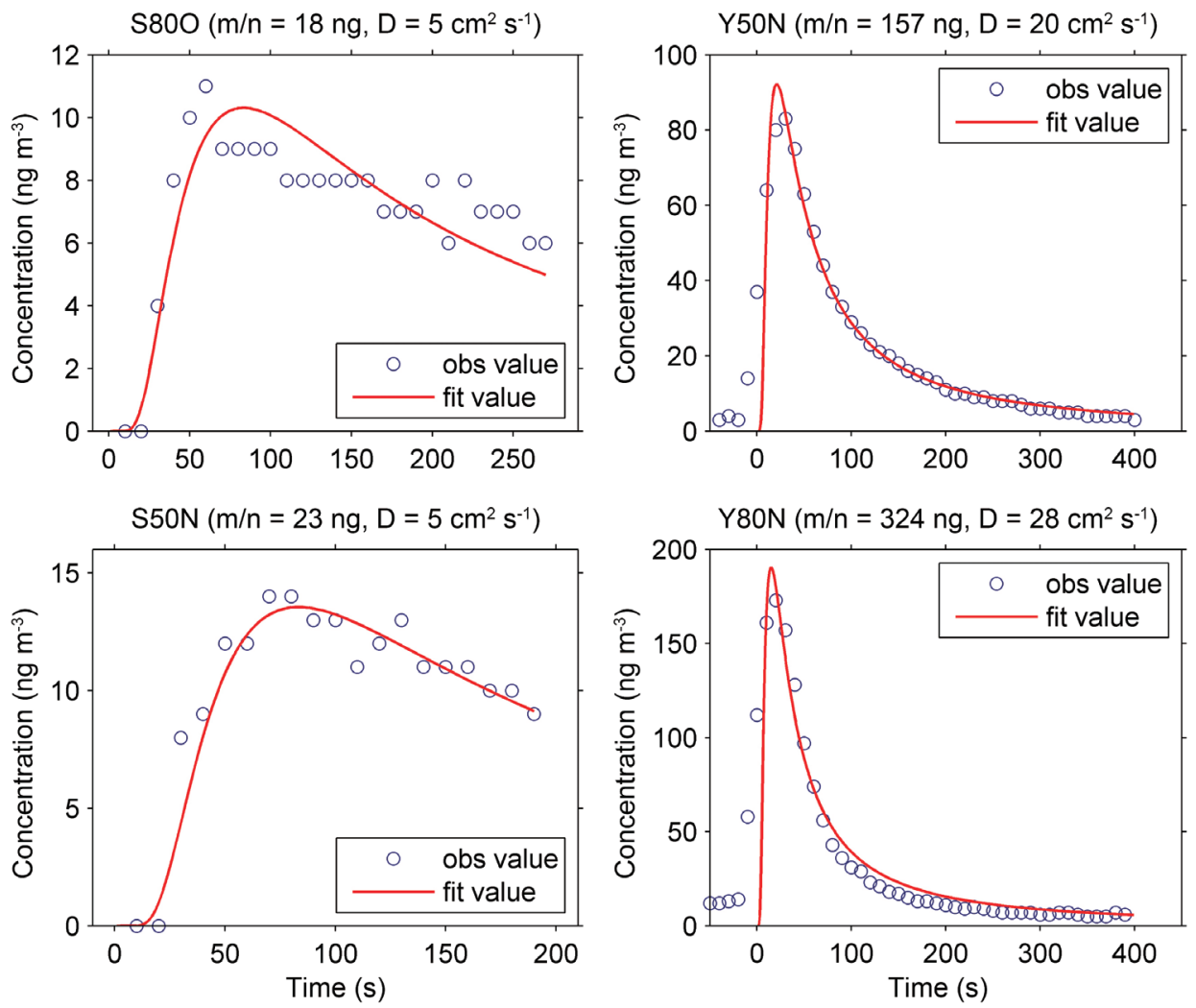

Fig. 3. The sampler type and test hole depth effects on the soil gas Hg concentration. S80O: columnar sampler in an old 80-cm-deep test hole; S50N: columnar sampler in a new 50-cm-deep test hole; Y50N: pyramidal sampler in a new 50-cm-deep test hole; Y80N: pyramidal sampler in a new 80-cm-deep test hole. (Color online only)

using the pyramidal sampler (Y50N) is almost eight times that measured using the columnar sampler (S50N). These results can be explained similarly to those for the hole depth study. As shown in Fig. 4, when the columnar sampler is inserted into the test hole, the gas inlet at the tip nearly contacts the soil. The gas volume below the sampler in the test hole is quite small. Therefore, the amount of soil gas that can diffuse from the surrounding soils into the test hole is quite limited. In contrast, when the pyramidal sampler is inserted into the test hole, the gas inlet is at a certain distance from the surrounding soil in the test hole, with the gas volume below the sampler in the test hole is still large. Consequently, the gas in the surrounding soils can easily diffuse into the test hole and be extracted by the pyramidal sampler. It is evident that the gas in the surrounding soil can more easily diffuse into the test hole when the pyramidal sampler is used for the soil gas measurements, resulting in higher measured soil gas $\mathrm{Hg}$ concentrations.

Based on this analysis, it can be concluded that the soil gas $\mathrm{Hg}$ concentration can be affected by the hole depth or sampler shape, and whether the hole has been used before has lower $\mathrm{Hg}$ concentration than a new drilling hole. Thus, when using the portable RA-915+ mercury vapour analyser for field measurements, new test holes should be used for instantaneous measurements. To compare data collected in the same area, the same sampler type and test hole depth should be employed. Here, a pyramidal sampler and a test hole depth of $80-100 \mathrm{~cm}$ is recommended for the soil gas Hg measurements.

\subsection{Soil Gas Hg Concentrations Across a Fault}

The $\mathrm{Hg}$ concentration in the soil is affected by the soil characteristics of the shallow surface layers (Gustin et al. 1997; Zhang and Lindberg 1999; Obrist et al. 2009; Moore and Castro 2012) and by deep tectonic activities, such as fault movements, volcanic activities, and seismic processes (Jin et al. 1989; Nriagu and Becker 2003; Zhang et al. 2014). Some carriers (underground water, $\mathrm{CO}_{2}$ and $\mathrm{CH}_{4}$ ) can gradually bring $\mathrm{Hg}$ from deep layers to the surface though pores, fractures and deep and large faults, leading to $\mathrm{Hg}$ accumulation in the surface soil or $\mathrm{Hg}$ release into the atmosphere. Thus, if faults or fractures develop under the surface layers, they provide good channels for $\mathrm{Hg}$ to migrate from deep layers to the surface, resulting in high $\mathrm{Hg}$ concentrations in the surface soil. Whether a fault is creeping or locking can also directly affect $\mathrm{Hg}$ migration from the deep layers to the surface. Just as other gases (e.g., Radon or Carbon dioxide), gaseous $\mathrm{Hg}$ activity growth from reverse faults to strike-slip and normal faults (Seminsky and Bobrov 2009), is consistent 


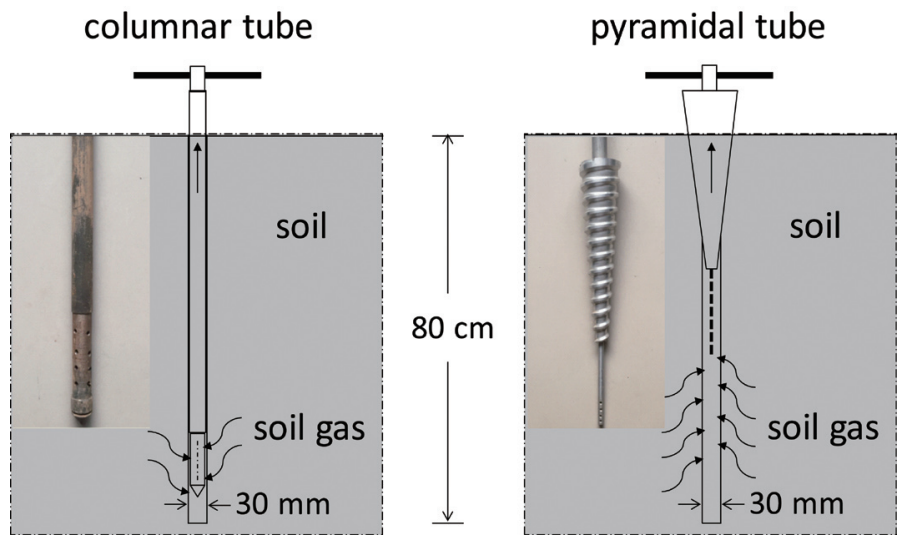

Fig. 4. Illustration of measurements using columnar and pyramidal samplers. (Color online only)

with greater emanation in extension zones relative to that in compressive structures (Utkin et al. 2006). The permeability of faults, other things being equal, should decrease in the series of faults formed under extension, shear, and compression, respectively. If a fault is affected by tensile stress (e.g., normal fault), its fault layers are creeping; in contrast, if a fault is affected by compressive stress (e.g., reverse fault), its fault layers are locked. Creeping faults are advantageous for $\mathrm{Hg}$ migration to the surface, whereas locked faults prevent upward $\mathrm{Hg}$ migration along the fault layers. $\mathrm{Hg}$ migrates by two mechanisms: independently of other chemical species with a relatively lower rate or via carriers (e.g., water or gas) with a relatively higher rate.

Field measurements were performed across the Beiluntai fault zone in Xinjiang Province, China to study soil gas $\mathrm{Hg}$ concentrations. The Beiluntai fault zone is a typical thrust fault with a certain degree of slipping subcomponents. The red line in Fig. 5a shows the fault zone along the near EW direction, and the white arrow indicates the direction of the relative motion of the blocks on both sides of the fault. The north side of the fault is the hanging wall and exhibits a topographic uplift. The south side of the fault is the footwall, which is flatter. Three sampling sites were chosen for these measurements at each of the following three locations: the hanging wall, fault zone and footwall (Fig. 5a). The LUMEX RA-915+ mercury vapour analyser with the pyramidal sampler was employed to perform measurements in 80-cm-deep test holes. Figure 6 shows the soil gas $\mathrm{Hg}$ concentration curves obtained at the nine sampling sites. The circles are the measured values, and the solid lines are the fitted curves obtained using Eq. (3). The sampling sites F1, F2, and F3 are located on the footwall on the south side of the Beiluntai fault, the central sampling sites F4, F5, and F6 are near the fault zone, and the north sampling sites F7, F8, and F9 are located on the hanging wall.

Figures 5 and 6 show that the soil gas concentrations at sampling sites F1, F2, and F3 on the fault footwall are quite high, whereas those at sampling sites F7, F8, and F9 on the fault hanging wall are quite low. The lowest concentrations are observed at sampling sites F4, F5, and F6 near the fault zone. As shown in Fig. 5b, the fitted $m / n$ values (soil gas $\mathrm{Hg}$ enrichment amounts) obtained using Eq. (3) are significantly lower for the sampling sites near the fault zone than for those on the hanging wall and footwall, but the $D$ values (diffusion coefficients) are similar at all of the sampling sites.

The Beiluntai fault is a thrust fault that is affected by the compressive force caused by regional tectonics. Its fault zone is sealed, which adversely affects $\mathrm{Hg}$ migration from the deep layers to the shallow soil layers along the fault zone. Therefore, $\mathrm{Hg}$ in the deep soil layers can only migrate through the hanging wall or footwall fractures on either side of the fault zone. Due to differences in the degrees of deformation in the hanging wall and footwall, their fractures exhibit different development degrees. The fault hanging wall is characterized mainly by uplift or bending deformation, which results in local tensile force on the surface and open fracture development (Fig. 5d). The resulting fractures are advantageous for soil gas release to the atmosphere. Consequently, gaseous $\mathrm{Hg}$ diffusing from the deep layers is continuously released to the atmosphere and therefore cannot be enriched. On the other hand, the footwall topography, which is affected by compressive forces, is quite flat. The surface fractures are mainly closed or semi-closed, which isn't suitable for gaseous $\mathrm{Hg}$ diffusion upward from the deep layers and its subsequent emission into the air. Thus, $\mathrm{Hg}$ gradually accumulates in the soil. In summary, the soil gas $\mathrm{Hg}$ concentrations across the north Beiluntai fault increase in the following order: near the fault zone, in the hanging wall and in the footwall. This pattern is due to the degree of $\mathrm{Hg}$ enrichment, i.e., the $\mathrm{m} / n$ value, observed in the shallow surface layer after $\mathrm{Hg}$ migrates upward from the deep soil layers.

These results show that the soil gas $\mathrm{Hg}$ concentrations across the fault zone are affected mainly by the fault zone development degree and the surface fractures and their degree 

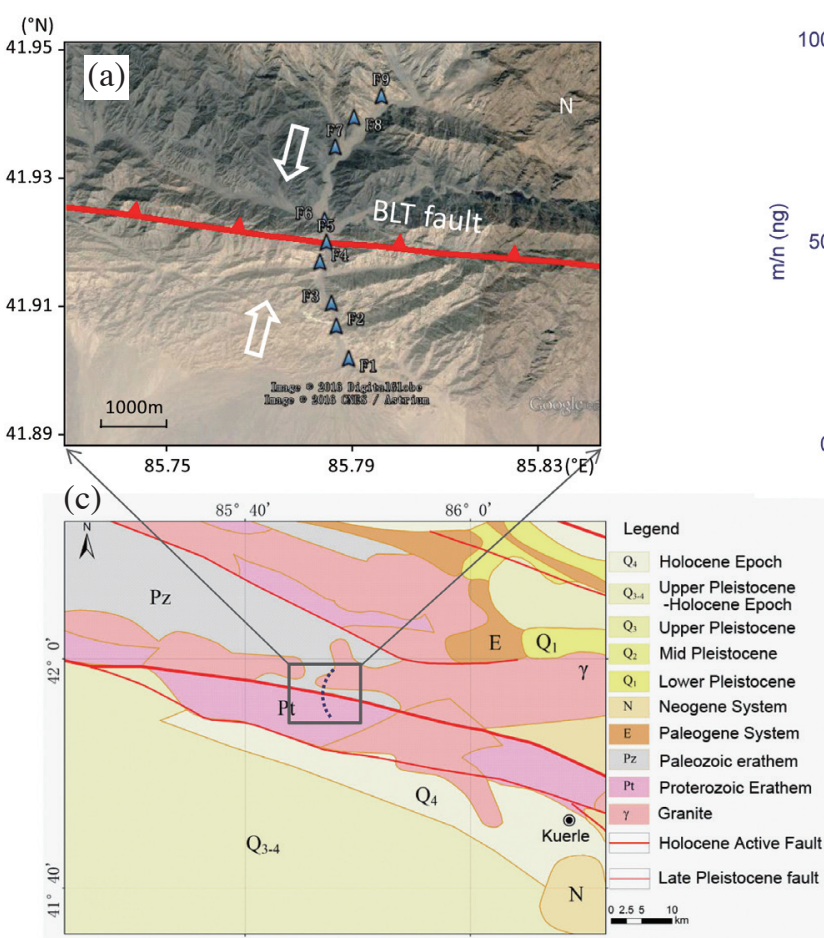

(b)

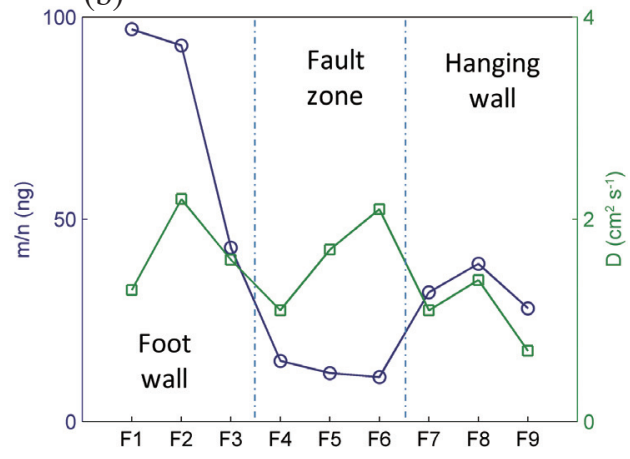

(d)

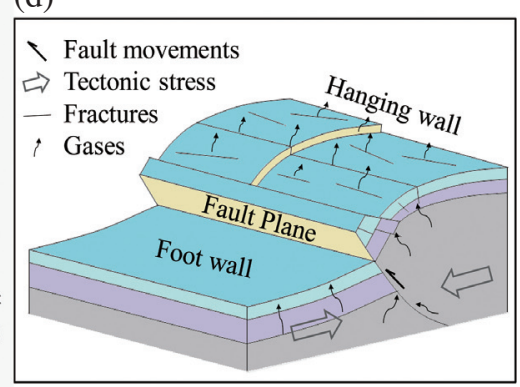

Fig. 5. Spatial distribution of the sampling sites at the north Beiluntai fault (a), fitting parameters for the gaseous Hg concentration curves (b), geological map around sampling points (c), and schematic diagram of thrust fault (d). (Color online only)
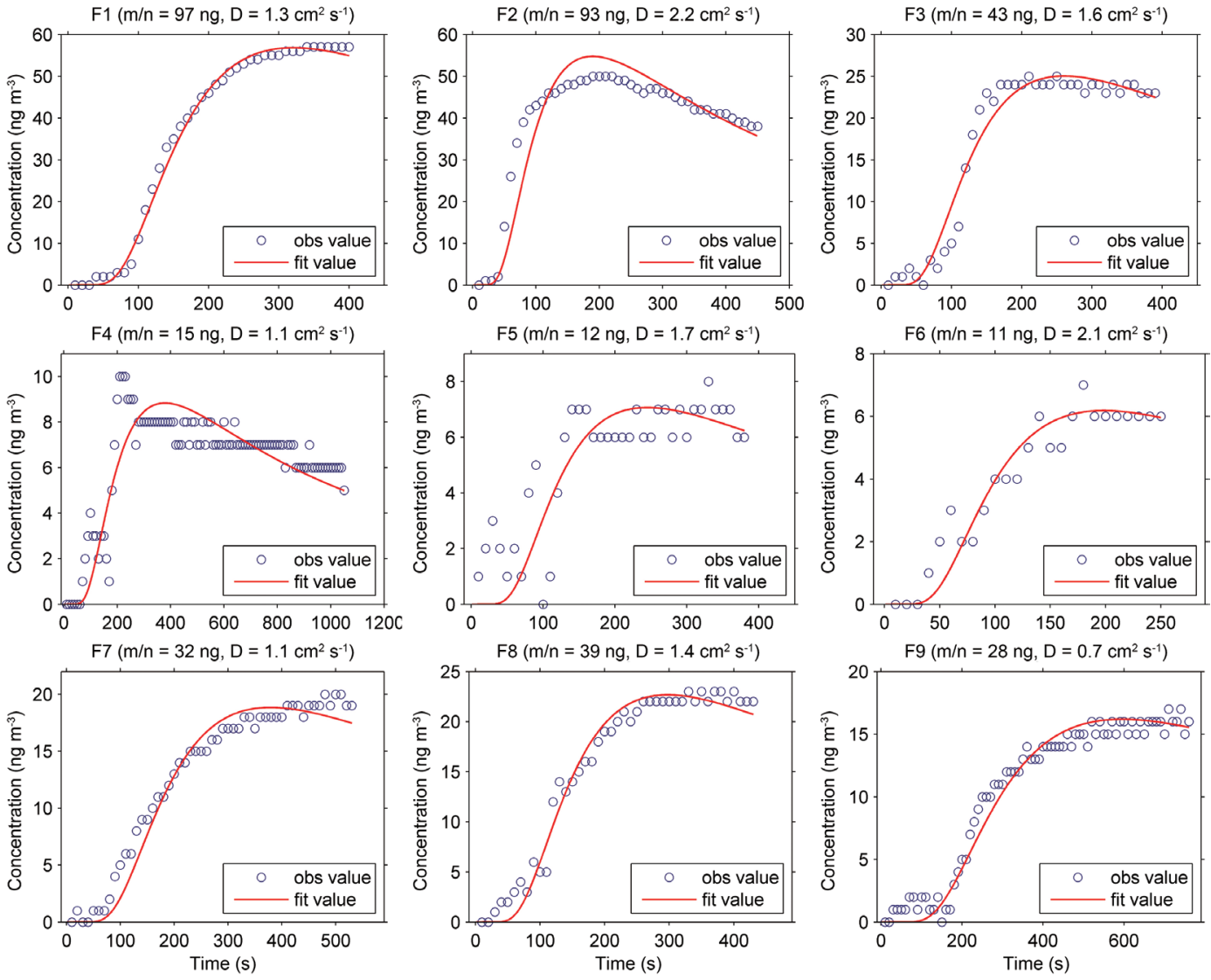

Fig. 6. Soil gas Hg concentrations measured across the Beiluntai fault and the corresponding fitted curves. (Color online only) 
of locking because these characteristics affect the surface enrichment of gaseous $\mathrm{Hg}$ that diffuses from deep soil layers to the surface in the fault zone or surrounding medium. If fault activity or the fault zone structure affects the soil gas $\mathrm{Hg}$ concentration, then large-scale tectonics also mainly impact the degree of enrichment $(\mathrm{m} / \mathrm{n})$ of this gaseous $\mathrm{Hg}$. In contrast, shallow surface soil properties effect (weathering layer) is insignificant; i.e., it does not significantly affect the diffusion coefficient $D$.

Rock type is also a main factor that affects the concentrations of gaseous Hg. From Fig. 5c, we can see the rock type in handing wall is granite, and in foot wall is Proterozoic shale. It is known that natural mercury in soil originates mainly from the parent rock; granite has the lowest mercury content (about $0.1 \mathrm{mg} \mathrm{kg}^{-1}$ ) while shale contains the highest amount of mercury (about $0.4 \mathrm{mg} \mathrm{kg}^{-1}$ ). Another reason for the significant change in gaseous $\mathrm{Hg}$ concentrations from hanging wall (F7 - F9) to foot wall (F1, F2) maybe the difference in rock type.

\subsection{Soil Gas Hg Concentrations Along a Fault}

The soil gas $\mathrm{Hg}$ concentration varies across fault zones due to differences in the structural deformation caused by tectonic forces in the fault zone. The concentration along the fault zone is also of interest. It is well known that due to the impacts of seismic activities and regional tectonism, fault healing, locking and deformation properties vary considerably along large fault zones. Thus, in this study, the soil gas $\mathrm{Hg}$ concentrations were measured along a typical strike-slip fault in West China, the Haiyuan fault zone (Liu-Zeng et al. 2007; Cavalié et al. 2008). The employed measurement method was similar to that used at the Beiluntai fault: the LUMEX RA-915+ mercury vapour analyser was used with the pyramidal sampler to sample 80-cm-deep test holes.

Figure 7 shows the soil gas $\mathrm{Hg}$ concentrations and the corresponding fitted curves at six sampling sites along the Haiyuan fault. The six sampling sites from east to west are Anyuan (AY), Santang (ST), Gaozao (GZ), Wanjia (WJ), Caiyuan $(\mathrm{CY})$, and Caowa $(\mathrm{CW})$. These sampling sites are all located at the fault zone (Fig. 8a), and similar measuring methods and conditions were employed during the soil gas $\mathrm{Hg}$ concentration measurements. The AY site is located at the Maomaoshan fault (F1), which is on the west side of the Haiyuan fault. The ST and GZ sites are located at the western section of the Haiyuan fault (F3). The WJ site is located at the middle section of the Haiyuan fault (F4), and the $\mathrm{CY}$ and $\mathrm{CW}$ sites are located at the eastern section of the Haiyuan fault (F5). Figure 8b presents the parameters $\mathrm{m} / \mathrm{n}$ and $D$ of the fitted curves for the six sampling sites. Figures 7 and 8 show that the soil gas $\mathrm{Hg}$ concentrations at the middle and eastern sections of the Haiyuan fault zone are quite low, whereas those at the western section (ST and GZ) are higher, indicating a higher degree of $\mathrm{Hg}$ enrichment in the soil, i.e., larger $m / n$ values. The diffusion coefficient $D$ is similar at all of the sampling sites, except at the ST sampling site, along the entire fault zone.

The Haiyuan fault zone is a typical strike-slip fault oriented along the NWW direction. The south side of the fault moves towards the right and is characterized by a slight topographic uplift, and the north side moves towards the left and has a flat terrain (Zhang et al. 1988). An 8.5 magnitude earthquake occurred on 12/16/1920 in the middle section of the Haiyuan fault. The slip rates and locking depths of the Haiyuan fault that were back-calculated using recent GPS data (Table 1) show that the western section of the Haiyuan fault has a deeper locking depth and smaller slip rate than the eastern and middle sections (Cui et al. 2009). From contrasting the GPS data results and gaseous $\mathrm{Hg}$ concentrations, we find that high slip rates are not conducive to mercury enrichment. Because higher slip rates may induce more fractures, which is the convenient access route for gaseous $\mathrm{Hg}$ diffusing from the deep layers into the atmosphere, and therefore cannot enrich mercury in shallow soils. Thus, the soil gas $\mathrm{Hg}$ concentrations measured in the shallow surface layers of the western section (F3) are higher than those of the eastern and middle sections (F5, F4). More than this, too large locking depth, as close to crust depth, means the access is sealed, and unfavourable to gaseous $\mathrm{Hg}$ migration. The Maomaoshan fault has a very deep locking depth $(22 \mathrm{~km})$, but the gaseous $\mathrm{Hg}$ concentration (AY) is lowest, in contrast with other sections.

Thus, the degree of $\mathrm{Hg}$ enrichment $(\mathrm{m} / \mathrm{n})$ in the shallow surface layers varies along the fault due to differences in the fault slip rates, locking depths, and healing degrees, and consequently, the soil gas $\mathrm{Hg}$ concentrations also vary along the fault. These factors do not have a significant impact on the diffusion coefficient $D$ in shallow soil.

Based on the above analysis the soil gas concentration along the fault is affected mainly by tectonics, the fault slip rate, the fault and fracture locking degrees, and the hanging and footwall degree of development. The $\mathrm{Hg}$ content that we measured in the soil contains two parts, diffusion and deposition. The Hg concentration in the soil is affected by the diffusion (migration velocity from the deep layers, associated with coefficient $D$ ), and also the deposition content (previously adsorbed/enriched in soil particles, associated with $m / n$ ). Fault/fractures are a good channel for gaseous mercury to migrate from the deep layers to the surface, but if the gas connects directly to the atmosphere, it will go against gaseous mercury enrichment in the surface soil. Assuming that a fault is connected to the deep layers, with sediments covering over it, gaseous mercury produced in the deep layers can migrate up along the fault, and enrich the shallow soil because of the sediment obstruction. If there are no sediments over the fault, gaseous mercury would continue to migrate up and escape into the atmosphere. Not only that, air will easily be absorbed into the shallow fault 
zone, diluting the $\mathrm{Hg}$ concentration.

Of course, the fault/fracture assumption as a channel for gaseous mercury migrating up has a premise; that the fault/fracture is in open or freely connected condition. As we know, a fault will slowly heal after an event/earthquake and close/lock due to tectonic force until the next event
(Meade and Hager 2005). In the early healing time, faultparallel velocities near fault zone are larger than in the late time, and gaseous mercury can migrate up from the deep layers along fault easier than in late periods. As time goes on, the fault will lock and the channel for gaseous mercury migration will be closed.
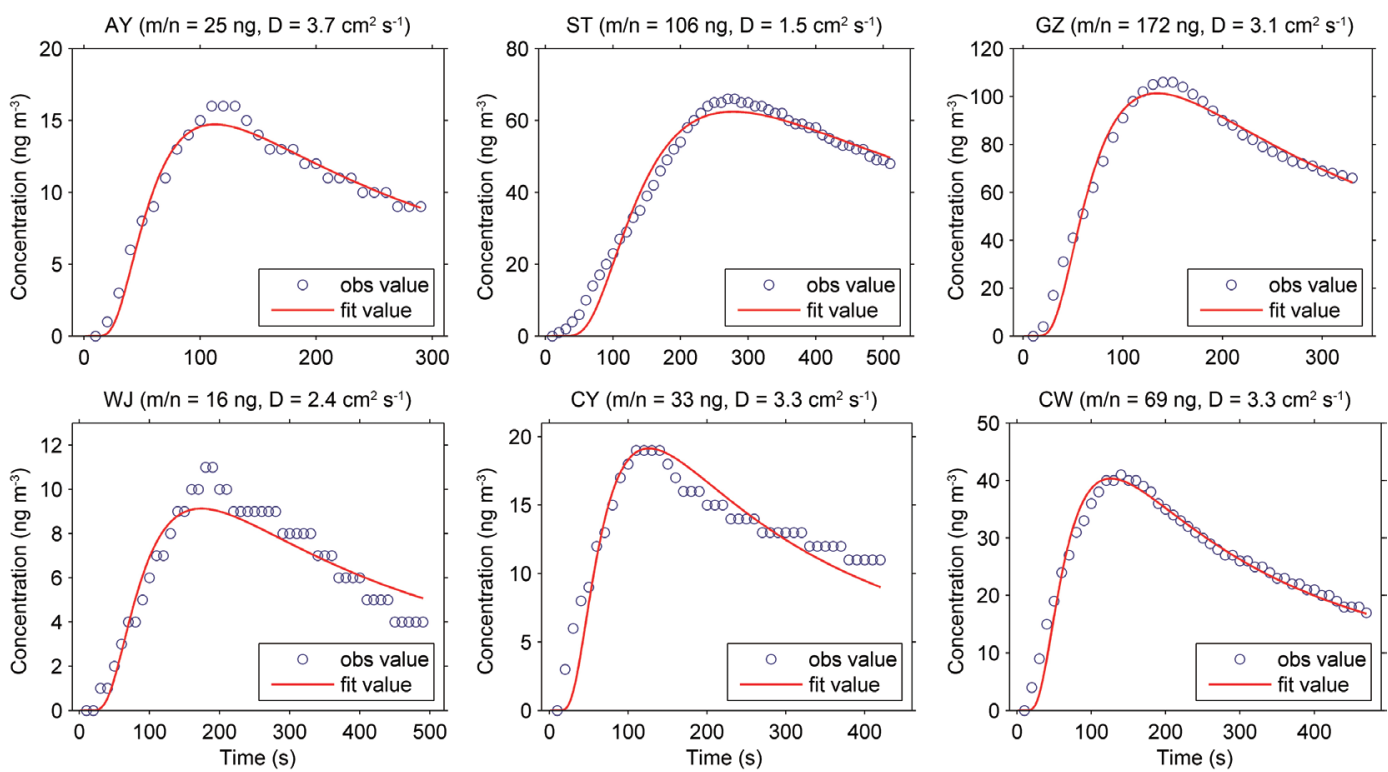

Fig. 7. Soil gas $\mathrm{Hg}$ concentrations along the Haiyuan fault and the corresponding fitted curves. (Color online only)
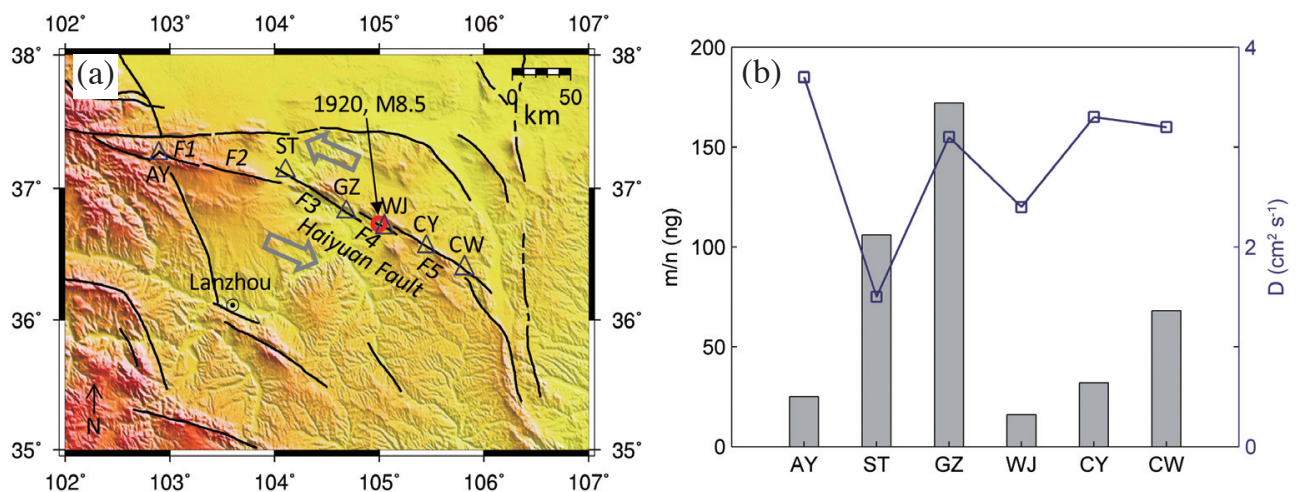

Fig. 8. Spatial distribution of the sampling sites along the Haiyuan fault (a) and fitting parameters for the corresponding gaseous Hg concentration curves (b). The open grey arrows indicate the directions of the relative motion of the blocks on both sides of Haiyuan fault. (Color online only)

Table 1. Fault slip rates and locking depths inversion results (Cui et al. 2009).

\begin{tabular}{ccccc}
\hline Fault (segment) & Length $(\mathbf{k m})$ & Locking depth $(\mathbf{k m})$ & Slip rates $\left(\mathbf{m m ~ a ~}^{-1}\right)$ & $\mathbf{~ m} / \mathbf{n}(\mathbf{n g})$ \\
\hline F1 & 37.37 & 22.0 & 3.5 & 25 \\
F2 & 68.01 & 10.3 & 6.5 & - \\
F3 & 80.56 & 8.4 & 4.0 & $106-172$ \\
F4 & 37.60 & 3.6 & 5.6 & 16 \\
F5 & 101.9 & 4.3 & 5.5 & $33-69$
\end{tabular}


Similar to the above pattern, $\mathrm{Hg}$ concentration in fault zone/fracture will change during changes in tectonic force. According to the qualitative soil gas concentration change pattern associated with stress change (Utkin and Yurkov 2010), assume that the measured $\mathrm{Hg}$ concentration per unit volume in soil gas at the initial stress corresponds to the $\mathrm{Hg}$ concentration. Under compression (stress increases and becomes greater than initial stress), the concentration first rises as the volume of cracks contracts, and then it falls after the cracks close. Later on, as the stress grows, rocks become subject to failure, weak links between pores break down, and radon activity increases notably. Under extension (stress decreases and becomes less than initial stress), concentration first falls as the volume of cracks expands, but then it rises after the cracks broaden and the pores open. Thus, some quasi-elastic strain exists in which compression and extension strains decrease or increase the $\mathrm{Hg}$ concentration, respectively.

The soil gas concentration along the fault is affected mainly by tectonics, the fault slip rate, the fault and fracture locking degrees. If the fault zone concentration is higher, there are no channels, and only weak connectivity with the atmosphere, as with the F3 segment in the Haiyuan fault. The F1 segments have low $\mathrm{Hg}$ concentration due to their deep locking depth, which is not conducive to gas migrating up. Although the F4 and F5 segments have good connectivity with the deep layer (small locking depth), their stronger activities (large slip rate) are good for gaseous mercury escaping into the atmosphere and not conducive to mercury soil enrichment. Our observation at the Beiluntai fault shows that the fault $\mathrm{Hg}$ concentration was low because the fault is locked, and the $\mathrm{Hg}$ concentration in the hanging wall was lower than that in the foot wall because the gaseous mercury easily escapes into the atmosphere from the tensile fractures in the hanging wall. In addition, if there is atresia in the fault zone, the parent rock will also affect the $\mathrm{Hg}$ concentration.

\subsection{Effects of the Soil Characteristics}

The factors discussed above can alter the upward $\mathrm{Hg}$ migration channels in the deep soil layers and influence the degree of $\mathrm{Hg}$ enrichment $(\mathrm{m} / \mathrm{n})$ at the surface. However, their effect on the diffusion coefficient $D$ is insignificant. The diffusion coefficient $D$ in Eq. (3) depends on the soil characteristics, such as the particle size, density, and porosity.

Figure 9 shows images of the surfaces in the research areas included in this study. The soil features (e.g., particle size, density, and porosity) are listed in Table 2 . The surface soil in the Changping District in Beijing is a typical Quaternary soil in the north China plain. The land in this area is used mainly as farmland. The surface soil is thus heavily affected by human activities. Because of irrigating and ploughing activities, the shallow soil has a low density $\left(0.7-1.0 \mathrm{~g} \mathrm{~cm}^{-3}\right)$ and high porosity $(0.55-0.65)$. Thus, the diffusion coeffi- cient in this area is large, in the range of $20-30 \mathrm{~cm}^{2} \mathrm{~s}^{-1}$ (the data were measured using the columnar sampler).

The Beiluntai fault is located at the southern edge of the Tianshan District in Xinjiang Province. The soil gas Hg concentration sampling sites were located mainly in mountain valleys where the surface soil is primarily fine sand or sandy soil sedimentary layers. The soil layer under the gravel is relatively dense, with Bulk density about $1.2-1.5 \mathrm{~g} \mathrm{~cm}^{-3}$, and has a low porosity $(0.32-0.35)$, which is unfavourable for soil gas diffusion. Thus, the diffusion coefficient in this area is small, in the range of $1-2 \mathrm{~cm}^{2} \mathrm{~s}^{-1}$.

The surface soil in the Haiyuan fault zone is a typical Loess Plateau Quaternary soil. Because of the dry climate it is not significantly affected by human activities, and the surface plants are mostly naturally grown dwarf grass. The surface soil in the Haiyuan fault zone is denser than that in the Changping District, but it is not as dense as fine sandy sedimentary layers. Thus, the soil gas $\mathrm{Hg}$ diffusion coefficient $D$ in the Haiyuan area lies between the Changping and Beiluntai soil diffusion values.

The Santang sampling site is a notable exception. Similar to Beiluntai, this sampling site is located in a valley between two mountains. The surface soil layer is a fine sandloess mixed sedimentary layer. Although the shallow soil layers at Santang are not as dense as those at Beiluntai, they are denser than Quaternary loess. Thus, the diffusion coefficient $D$ measured at the Santang sampling site is $1.5 \mathrm{~cm}^{2} \mathrm{~s}^{-1}$, which is slightly higher than that measured at Beiluntai but lower than that measured at the Haiyuan fault zone.

\section{CONCLUSIONS}

The soil gas $\mathrm{Hg}$ concentrations in the north China plain, Loess Plateau, Changping District, Haiyuan fault zone, and Beiluntai fault at the edge of south Tianshan were measured using a LUMEX RA-915+ mercury vapour analyser. A theoretical gas diffusion equation was employed to analyse the influence factors, including the sampler type, test hole depth, soil characteristics, fault characteristics, and their effects on the soil gas $\mathrm{Hg}$ concentration measurements. The following conclusions were drawn:

(1) The measured soil gas Hg concentrations are generally consistent with the theoretical gas diffusion equation analytical solution. The shape of the measurement curve is closely related to the degree of $\mathrm{Hg}$ enrichment in the soil $(m / n)$ and the soil density $(D)$.

(2) The soil gas Hg concentration is affected mainly by the time lapse between the test hole drilling and the measurement, the test hole depth, and the sampler shape. We recommend that newly drilled test holes be used for each measurement, which should be performed immediately after the hole is drilled. Furthermore, when comparing regional results, the sampler and the measurement hole depth should be the same. 

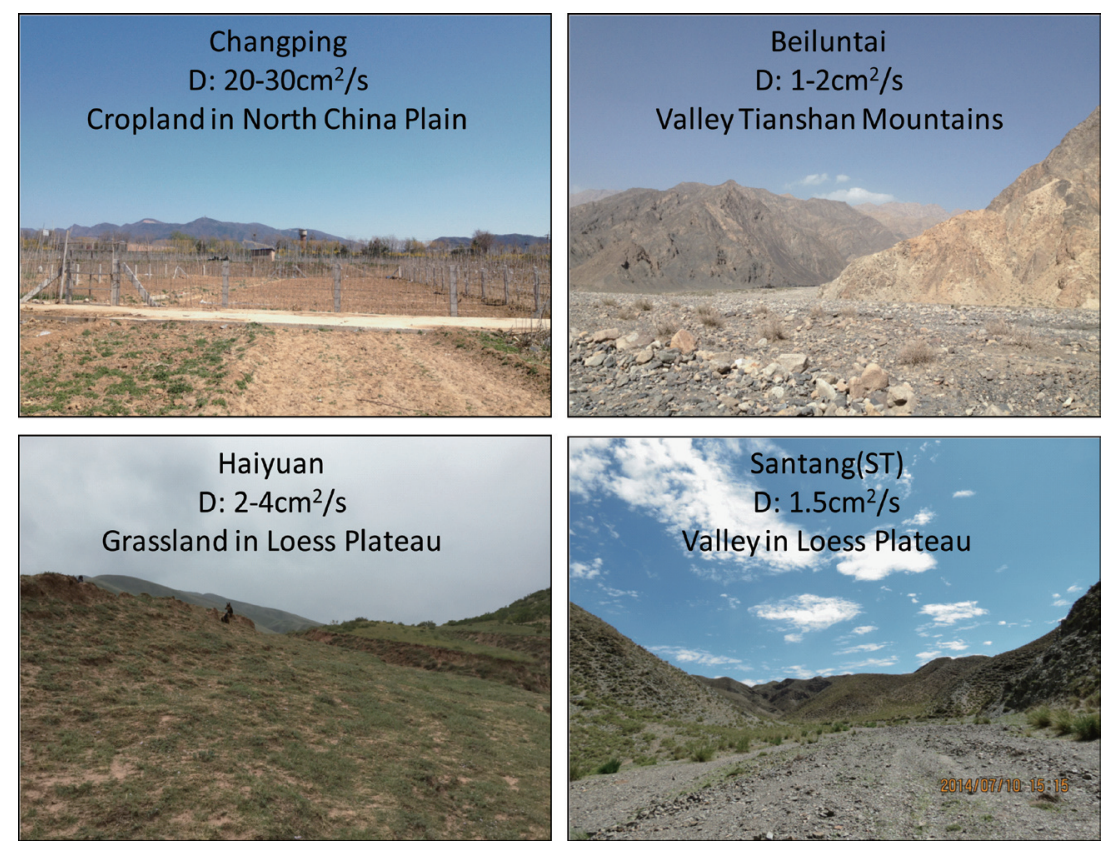

Fig. 9. Diffusion coefficient $D$ in soils with different characteristics. (Color online only)

Table 2. Soil characteristics in different areas (Lin 2002).

\begin{tabular}{ccccc}
\hline Areas & Particle Size $(\mathbf{m m})$ & Bulk density $\left(\mathrm{g} \mathrm{cm}^{-3}\right)$ & Porosity & Diffusion coefficient $\left(\mathbf{c m}^{2} \mathbf{~ s}^{-1}\right)$ \\
\hline Changping & $0.01-0.02$ & $0.7-1.0$ & $0.55-0.65$ & $20-30$ \\
Haiyuan & $0.02-0.05$ & $1.0-1.3$ & $0.45-0.55$ & $2-4$ \\
Beiluntai & $0.25-0.5$ & $1.2-1.5$ & $0.32-0.35$ & $1-2$ \\
Santang & $0.1-0.5$ & $1.3-1.5$ & $0.35-0.42$ & 1.5 \\
\hline
\end{tabular}

(3) Across a fault the soil gas $\mathrm{Hg}$ concentration is affected mainly by the fractures degree of development in the fault zone and their locking degree. These factors affect the degree of $\mathrm{Hg}$ enrichment $(\mathrm{m} / \mathrm{n})$ due to upward $\mathrm{Hg}$ migration from the deep layers, but they do not have a significant effect on the diffusion coefficient $D$ in the shallow weathered soil layer.

(4) Along a fault the $\mathrm{Hg}$ enrichment degree $(\mathrm{m} / \mathrm{n})$ in the shallow surface layer might vary due to differences in the fault slip rate, locking degree and healing degree, but the diffusion coefficient $D$ in the shallow soil layers is not significantly influenced by these factors.

Overall, tectonics, rock type, the fault slip rate, the fault and fracture locking degrees, and the hanging and footwall degrees of development affect the soil gas concentration in a fault zone because they can alter the $\mathrm{Hg}$ upward migration channels in the deep layers and the $\mathrm{Hg}$ enrichment degree at the surface $(\mathrm{m} / \mathrm{n})$. However, these factors do not significantly impact the diffusion coefficient $D$ in shallow soil layers. The diffusion coefficient $D$ depends on the particle size, density and porosity of the soil materials.
Acknowledgements The authors thank the researchers and staff at the Gansu Seismological Bureau and the Seismological Bureau of Ningxia-Hui Autonomous Region for their assistance with field work. The authors also thank Guomeng Zhang and Lei Zhang from the Institute of Crustal Dynamics, China Earthquake Administration; Bo Wang from the China Earthquake Network Centre; Zhen Fang from the Anhui Seismological Bureau; Hejun Su from the Gansu Seismological Bureau; and Long Yan from the Seismological Bureau of the Xinjiang Uygur Autonomous Region for their help and guidance. The authors also thank the Two Anonymous Reviewers for their constructive comments. This study was supported by basic research and public service special funding from the Central Research Institutes (ZDJ2014-08), the special funding project for Scientific Research of the Seismological Industry (201408019-03), and the National Natural Science Foundation of China (41502239).

\section{REFERENCES}

Aral, M. M. and B. Liao, 1996: Analytical solutions for 
two-dimensional transport equation with time-dependent dispersion coefficients. J. Hydrol. Eng., 1, 20-32, doi: 10.1061/(ASCE)1084-0699(1996)1:1(20). [Link]

Cavalié, O., C. Lasserre, M. P. Doin, G. Peltzer, J. Sun, X. $\mathrm{Xu}$, and Z. K. Shen, 2008: Measurement of interseismic strain across the Haiyuan fault (Gansu, China), by InSAR. Earth Planet. Sci. Lett., 275, 246-257, doi: 10.1016/j.eps1.2008.07.057. [Link]

Chen, C. X. and G. M. Li, 1996: Theory and model of solute transport in groundwater. Wuhan: China University of Geosciences Press, 32-36. (in Chinese)

Choi, H. D. and T. M. Holsen, 2009: Gaseous mercury emissions from unsterilized and sterilized soils: The effect of temperature and UV radiation. Environ. Pollut., 157, 1673-1678, doi: 10.1016/j.envpol.2008.12.014. [Link]

Cordy, P., M. M. Veiga, I. Salih, S. Al-Saadi, S. Console, O. Garcia, L. A. Mesa, P.C. Velásquez-López, and M.Roeser, 2011: Mercury contamination from artisanal gold mining in Antioquia, Colombia: The world's highest per capita mercury pollution. Sci. Total Environ., 410411, 154-160, doi: 10.1016/j.scitotenv.2011.09.006. [Link]

Cui, D., Q. Wang, Y. Hu, W. Wang, and G. Zhu, 2009: Inversion of GPS data for slip rates and locking depths of the Haiyuan fault. Acta Seismol. Sin., 31, 516-525. (in Chinese)

Gu, B., Y. Bian, C. L. Miller, W. Dong, X. Jiang, and L. Liang, 2011: Mercury reduction and complexation by natural organic matter in anoxic environments. Proc. Natl. Acad. Sci. USA, 108, 1479-1483, doi: 10.1073/ pnas.1008747108. [Link]

Gustin, M. S., G.E. Taylor Jr., and R. A. Maxey, 1997: Effect of temperature and air movement on the flux of elemental mercury from substrate to the atmosphere. J. Geophys. Res., 102, 3891-3898, doi: 10.1029/96JD02742. [Link]

Jin, Y., Z. Wu, C. Shen, J. Wei, and H. Zhu, 1989: Earthquake prediction through the observation and measurement of mercury content variation in water. $J$. Geochem. Explor., 33, 195-202, doi: 10.1016/03756742(89)90029-0. [Link]

Johnson, D. W . and S. E. Lindberg, 1995: The biogeochemical cycling of $\mathrm{Hg}$ in forests: Alternative methods for quantifying total deposition and soil emission. $\mathrm{Wa}$ ter Air Soil Pollut., 80, 1069-1077, doi: 10.1007/ BF01189767. [Link]

Li, Y.,J.Du, X.Wang, X.Zhou, C.Xie, and Y.Cui, 2013: Spatial variations of soil gas geochemistry in the Tangshan area of Northern China. Terr. Atmos. Ocean. Sci., 24, 323-332, doi: 10.3319/TAO.2012.11.26.01(TT). [Link]

Lin, C. J., M. S. Gustin, P. Singhasuk, C. Eckley, and M. Miller, 2010: Empirical models for estimating mercury flux from soils. Environ. Sci. Technol., 44, 8522-8528, doi: 10.1021/es1021735. [Link]

Lin, D. Y. 2002: Agrology. Beijing: Chinese Forestry Publishing House, 231-256. (in Chinese)

Liu, Y., 2006: Review of the research progress on the seismological science of underground fluid in China during last 40 years. Earthquake Res. China, 22, 222-223. (in Chinese)

Liu-Zeng, J., Y. Klinger, X. Xu, C. Lasserre, G. Chen, W. Chen, P. Tapponnier, and B. Zhang, 2007: Millennial recurrence of large earthquakes on the Haiyuan fault near Songshan, Gansu Province, China. Bull. Seismol. Soc. Am., 97, 14-34, doi: 10.1785/0120050118. [Link]

Meade, B. J. and B. H. Hager, 2005: Block models of crustal motion in southern California constrained by GPS measurements. J. Geophys. Res., 110, B03403, doi: 10.1029/2004JB003209. [Link]

Meili, M., 1991: The coupling of mercury and organic matter in the biogeochemical cycle - Towards a mechanistic model for the boreal forest zone. Water Air Soil Pollut., 56, 333-347, doi: 10.1007/BF00342281. [Link]

Moore, C. W. and M. S. Castro, 2012: Investigation of factors affecting gaseous mercury concentrations in soils. Sci.Total Environ., 419, 136-143, doi: 10.1016/j.scitotenv.2011.12.068. [Link]

Moore, C. W., M. S. Castro, and S. B. Brooks, 2011: A simple and accurate method to measure total gaseous mercury concentrations in unsaturated soils. Water Air Soil Pollut., 218, 3-9, doi: 10.1007/s11270-010-06917. [Link]

Nriagu, J. and C. Becker, 2003: Volcanic emissions of mercury to the atmosphere: Global and regional inventories. Sci. Total Environ., 304, 3-12, doi: 10.1016/ S0048-9697(02)00552-1. [Link]

Obrist, D., D. W. Johnson, and S. E. Lindberg, 2009: Mercury concentrations and pools in four Sierra Nevada forest sites, and relationships to organic carbon and nitrogen. Biogeosciences, 6, 765-777, doi: 10.5194/bg6-765-2009. [Link]

Schuster, E. 1991: The behavior of mercury in the soil with special emphasis on complexation and adsorption processes - A review of the literature. Water Air Soil Pollut., 56, 667-680, doi: 10.1007/BF00342308. [Link]

Seminsky, K. Z. and A. A. Bobrov, 2009: Radon activity of faults (western Baikal and southern Angara areas).Russ.Geol.Geophys., 50, 682-692, doi: 10.1016/j. rgg.2008.12.010. [Link]

Sholupov, S., S. Pogarev, V. Ryzhov, N. Mashyanov, and A. Stroganov, 2004: Zeeman atomic absorption spectrometer RA-915+ for direct determination of mercury in air and complex matrix samples. Fuel Process. Technol., 85, 473-485, doi: 10.1016/j.fuproc.2003.11.003. [Link]

Sigler, J. M. and X. Lee, 2006: Gaseous mercury in background forest soil in the northeastern United States. 
J. Geophys. Res., 111, G02007, doi: 10.1029/2005JG000106. [Link]

Skyllberg, U., P. R. Bloom, J. Qian, C. M. Lin, and W. F. Bleam, 2006: Complexation of mercury(II) in soil organic matter: EXAFS evidence for linear two-coordination with reduced sulfur groups. Environ. Sci. Technol., 40, 4174-4180, doi: 10.1021/es0600577. [Link]

Špirić, Z. and N. R. Mashyanov, 2000: Mercury measurements in ambient air near natural gas processing facilities. Fresen. J. Anal. Chem., 366, 429-432, doi: 10.1007/s002160050087. [Link]

Stoffers, P., M. Hannington, I. Wright, P. Herzig, C. de Ronde, and S. S. Party, 1999: Elemental mercury at submarine hydrothermal vents in the Bay of Plenty, Taupo volcanic zone, New Zealand. Geology, 27, 931934, doi: 10.1130/0091-7613(1999)027<0931:EMAS $\mathrm{HV}>2.3 . \mathrm{CO} ; 2$. [Link]

Tang, C., Y. Wang, and H. Fu, 2004: Characteristics of short-term synthetical anomalies of radon and mercury content in groundwater in Sichuan-Yunnan Region before strong earthquakes. J.Seismol. Res., 27, 18-22. (in Chinese)

Utkin, V. I. and A. K. Yurkov, 2010: Radon as a tracer of tectonic movements. Russ. Geol. Geophys., 51, 220227, doi: 10.1016/j.rgg.2009.12.022. [Link]

Utkin, V. I., E. Mamyrov, M. V. Kan, S. V. Krivasheev, A. K. Yurkov, I. I. Kosyakin, and A. N. Shishkanov, 2006: Radon monitoring in the Northern Tien Shan with application to the process of tectonic earthquake nucleation. Izv., Phys. Solid Earth, 42, 775-784, doi: 10.1134/S1069351306090072. [Link]
Wang, C. M., X. H. Li, and B. L. Wei, 1991: Applications of measurement of fracture gases in seismological sciences. Beijing: Seismological Press, 44-165. (in Chinese)

Wang, G., C. Liu, J. Wang, W. Liu, and P. Zhang, 2006: The use of soil mercury and radon gas surveys to assist the detection of concealed faults in Fuzhou City, China. Environ. Geol., 51, 83-90, doi: 10.1007/s00254006-0306-1. [Link]

Zárate-Valdez, J. L., R. J. Zasoski, and A. E. Läuchli, 2006: Short-term effects of moisture content on soil solution pH and soil Eh. Soil Sci., 171, 423-431.

Zhang, F., J. Ren, H. Li, Y. Zhang, and C. Wang, 2005: Relationship between the anomalies of underground fluid in the Huailai NO.4 well and earthquake. Seismol. Geol., 27, 123-130, doi: 10.3969/j.issn.02534967.2005.01.014. (in Chinese) [Link]

Zhang, H. and S. E. Lindberg, 1999: Processes influencing the emission of mercury from soils: A conceptual model. J. Geophys. Res., 104, 21889-21896, doi: 10.1029/1999JD900194. [Link]

Zhang, L., Y. Liu, L. Guo, D. Yang, Z. Fang, T. Chen, H. Ren, and B. Yu, 2014: Isotope geochemistry of mercury and its relation to earthquake in the Wenchuan Earthquake Fault Scientific Drilling Project Hole1 (WFSD-1). Tectonophysics, 619-620, 79-85, doi: 10.1016/j.tecto.2013.08.025. [Link]

Zhang, P., P. Molnar, B. C. Burchfiel, L. Royden, Y. Wang, Q. Deng, F. Song, W. Zhang, and D. Jiao, 1988: Bounds on the Holocene slip rate of the Haiyuan fault, north-central China. Quat. Res., 30, 151-164, doi: 10.1016/0033-5894(88)90020-8. [Link] 